\title{
Chapter 4 \\ Sexual and Reproductive Health and Rights Inequities Among Sex Workers Across the Life Course
}

\author{
Ania Shapiro and Putu Duff
}

\section{Sexual and Reproductive Health: A Fundamental Human Right}

The highest attainable standard of sexual and reproductive health (SRH) is a fundamental human right [1-4], affirmed through numerous international and national laws and mandates including the Universal Declaration of Human Rights [5], the International Conference on Population and Development [6], and the Convention on the Elimination of All Forms of Discrimination against Women [1]. Sexual and reproductive rights recognise the basic rights of all individuals to access information, SRH services, and the means and supports to make informed decisions about their SRH, including the spacing and timing of children [1]. All individuals are entitled to exercise their SRH rights free from coercion, discrimination, and violence [6]. SRH and rights continue to be featured prominently on the international agenda, including in the United Nations' Sustainable Development Goal number 5, which strives to ensure universal access to SRH and rights [7].

Data SourceMuch of the information, including the methods and results contained in this chapter, were based on the Global Network of Sex Work Projects' Briefing paper, entitled "Sex Workers' Access to Comprehensive Sexual and Reproductive Health Services" available at: https://www. nswp.org/sites/nswp.org/files/bp_sws_access_to_comp_srh_-_nswp_2018.pdf

\footnotetext{
A. Shapiro

Sex Workers Outreach Project (SWOP-Tucson), Tucson, AZ, USA

P. Duff $(\bowtie)$

Centre for Gender and Sexual Health Equity, Vancouver, BC, Canada

Faculty of Medicine, University of British Columbia, Vancouver, BC, Canada

e-mail: putu.duff@cgshe.ubc.ca
} 


\section{Structural Determinants of Sexual and Reproductive Health Access for Sex Workers}

Sex workers experience a multitude of overlapping structural barriers that impede their fundamental SRH rights, including access to SRH care. SRH care encompasses a range of services such as: maternal and newborn care (e.g. antenatal, perinatal, and postnatal care); family planning services (e.g. contraceptives, fertility services, and safe abortions); and services that address HIV/STIs, HPV-related cancer prevention, and other reproductive-tract morbidities. The criminalisation of sex work is one of the most formidable barriers to SRH care, as it limits access to and use of health services [8-10] on the part of sex workers, and undermines their access to condoms, including the right to carry condoms and negotiate their use $[9,11,12]$, either independently or as part of the practice of using dual contraceptive methods [13]. Criminalisation can also undermine HIV testing [14], access to social services and support [15]; plus, it increases the incidence of HIV/STIs and physical/sexual violence $[9,16]$.

In many settings, the harmful impacts of the criminalisation of sex work are compounded by other rights-violating laws and policies, including the criminalisation of HIV, of same-sex relationships, and of gender non-conformance, e.g. laws against "crossdressing" or "impersonating the opposite sex", which further exacerbate SRH inequities among transgender and male sex workers [17].

The widespread criminalisation of sex work is often based on portrayals of sex workers as either dangerous, immoral individuals, or as helpless victims - and often as victims of human trafficking. Criminalisation, together with the prevalence of vilifying depictions of sex workers, has far-reaching implications, perpetuating stigma, violence [16], and fueling the exclusion of organisations serving sex workers from receiving HIV and health funding. A striking example of this is the U.S. President's Emergency Plan for AIDS Relief (PEPFAR's) Anti-Prostitution Loyalty Pledge, which, until 2013, funded only US organisations (and their foreign sub-grantees) opposing prostitution, and which continues to restrict funding, to organisations outside of the United States.

The SRHR of sex workers are further undermined by policies restricting women's SRHR more broadly, including the criminalisation of abortion, and other policies and efforts which restrict access to safe abortion. In 2017, the Mexico City policy_known also as the Global Gag rule-was expanded to include all US government aid, preventing organisations from receiving US funding if they engage in any abortion-related activities, including offering abortion information, services, referrals, and/or advocating for abortion law reform. Furthermore, organisations are excluded from receiving funding even if abortion-related information and services are provided by another donor.

The criminalisation and stigmatisation of sex work influence community perceptions of sex workers, reinforcing stigma and discrimination both in healthcare settings and in day-to-day life [18]. As a result, sex workers are often denied equal access to quality health services and may experience difficulties accessing SRH 
care across their life course [19-24]. Together, these overlapping structural barriers contribute to a lack of targeted services, thus violating the right of sex workers to comprehensive and appropriate SRH care.

\section{Gaps in Comprehensive Sexual and Reproductive Health Services Across the Life Course}

While sex workers are entitled to the full spectrum of SRH rights, for this population, critical gaps in the provision of SRH services remain. Closing the gap in SRHR for sex workers continues to be a global priority, with the 2016 Committee on Economic, Social and Cultural Rights' recommendations underscoring the need to protect sex workers from violence, coercion, and discrimination, and to ensure their access to sexual and reproductive healthcare services across the life course [2].

Nonetheless, at the expense of this population's broader SRH needs, the dominant view on the part of public health authorities of sex workers as "vectors of disease" [25] has perpetuated a narrow focus on the prevention, testing, and treatment interventions of HIV and sexually transmitted infection (STI). While sex workers are particularly vulnerable to HIV and other STIs, they often lack access to routine SRH screening, including reproductive-tract screening. Female sex workers, for example, are disproportionately affected by high-risk strains of the human papillomavirus (HPV) [26] and cervical cancer [27], but cervical screening among sex workers remains low [28, 29].

The gap in SRH screening is particularly pronounced for male sex workers, whose SRH needs are poorly understood and are often conflated with those of gay men and men who have sex with men (MSM) [30]. The paucity of data on male sex workers' health has contributed to the near-complete absence of targeted SRH services, including screening for anorectal STIs and anal cancers [31].

Similarly, while transgender sex workers bear a high burden of STIs [32], including HIV (estimates from 2012 placed the global prevalence at 19\%) [33], the holistic SRH needs of transgender sex workers are seldom acknowledged. Data available on transgender sex workers focus almost exclusively on STIs and HIV [34, 35], and are often limited by small sample sizes and/or failure to disaggregate transgender women from MSM. The near-complete lack of data on the SRH needs of sex working transgender men means the SRHR of these workers remain even less visible. Transgender sex workers contend with myriad social and structural forces driving SRH inequities, including pervasive violence, and gender-related stigma and discrimination, which can occur within health settings [36]. Gender-sensitive SRH care, including counselling and referrals to or provision of hormone therapy, and other gender-affirming services, are essential SRH services for transgender sex workers $[37,38]$. Such services remain scarce and, where available, are rarely integrated into existing SRH programming. 
Globally, sex workers experience high rates of unintended pregnancies [39, 40]. For example, $53 \%$ of sex workers in a Colombian study reported having had at least one induced abortion [41]. In a study conducted in Uzbekistan [42], roughly a quarter of sex workers reported having had three or more abortions. Such high rates of unintended pregnancies have been attributed to a number of structural factors, including criminalisation, gender-based violence, and difficulties negotiating client condom use [39-42]. In poorly resourced settings in particular, there is significant unmet need for effective contraceptive methods [43-47], especially voluntary access to long-acting reversible contraceptives such as intrauterine devices and implants. For instance, while $53 \%$ of sex workers in a Colombian study reported having had an abortion, $17 \%$ reported using no contraceptive methods at all [41]. In Cambodia, only $10 \%$ of sex workers reported using hormonal contraceptives [43]. Similarly, a study across three Russian cities documented that only one-third of sex workers used contraceptive methods other than condoms [45].

Significant challenges to accessing effective contraception include the availability and cost of services, plus the distances involved in accessing them. Due to limited access to family planning and contraceptive counselling services, sex workers may also receive less information about the effective use and potential side effects of contraceptives [48]. In some cases, sex workers are not even offered the full range of effective contraceptives [25].

Many sex workers also lack access to safe and affordable abortion procedures [49-52], particularly in contexts where abortion is criminalised. For example, a qualitative study in Brazil revealed that most sex workers seeking abortions used illegally acquired misoprostol, and many of these procedures resulted in serious health complications including haemorrhaging and the need for hospitalisation [50]. There remains a near-dearth of data when it comes to sex workers on the subject of their needs or requirements for care post-abortion, despite the high rates of (often unsafe) abortion in this population.

The SRH needs of sex workers who are pregnant, parenting, or who wish to become pregnant, also remain unmet, including access to essential services such as prenatal, delivery, and postnatal care [53]. The SRHR needs of pregnant and parenting SWs remain inadequately addressed in both health systems and research, partly owing to public perceptions of sex workers as unlikely or unfit parents. However, sex work and parenthood are intimately entwined: many sex workers have children, and many support dependent children. One study among Kenyan sex workers reported that almost $90 \%$ had dependent children [54]. Emerging evidence suggests sex workers have pregnancy intentions similar to women in other occupations [55, 56]. However, numerous social and structural barriers - the criminalisation of sex work [57], stigma, and lack of appropriate, low-barrier services — create challenges for parenting sex workers by limiting access to and engagement with pregnancyrelated SRH services. Reduced access to safe conception services (including preconception counselling), as well as pre- and postnatal care, may result in serious SRH and rights violations at a critical time in the reproductive lives of sex workers [56]. Furthermore, personal accounts reveal serious violations to their reproductive 
choices, including coerced sterilisation and abortions, as well as the disproportionate removal of children from sex workers, due to their parents' occupation [13].

This chapter draws from research conducted by the Global Network of Sex Work Projects (NSWP) for its Briefing Paper, "Sex Workers' Access to Comprehensive Sexual and Reproductive Health Services" [58]. NSWP uses a methodology that ensures the grassroots voices of sex workers and sex worker-led organisations are heard. While identifying global trends, this process documents issues faced by sex workers at local, national, and regional levels. The NSWP Secretariat manages the production of briefing papers and conducts consultations among its members to document evidence. To do this, NSWP contracts:

- Global Consultants to undertake desk research and global e-consultations with NSWP member organisations, coordinate and collate inputs from National Consultants, analyse regional differences, and draft the global briefing papers.

- National Consultants to gather information and document country case studies

This chapter presents excerpts gathered from in-depth interviews, focus group discussions, and a global e-consultation conducted by NSWP with member organisations in September to October of 2017. National consultants conducted in-depth interviews and focus group discussions (FGDs) with 171 male, female, and transgender sex workers across ten countries (Austria, Bahamas, Canada, El Salvador, Indonesia, Kyrgyzstan, Namibia, Nepal, Peru, and Rwanda), using a standardised interview/FGD questionnaire designed to elicit the experiences of sex workers when accessing SRH services. The same questionnaire was distributed throughout the NSWP network, garnering 13 responses from NSWP member organisations.

Responses gathered from the interviews, focus groups, and e-consultation were analysed to identify global trends, and organised by theme. In this chapter, we present the most prominent themes emerging from this consultation, alongside representative quotes illustrating each theme. All quotes and findings presented in this chapter originate from the NSWP Briefing Paper, "Sex Workers' Access to Comprehensive Sexual and Reproductive Health Services", and its accompanying research.

\section{Barriers to Accessing SRH Services and Rights: Findings from In-Depth Interviews and Focus Groups}

\section{Widespread Criminalisation, Discrimination, and Stigmatisation in Healthcare Settings}

The direct and indirect criminalisation of sex work was found to simultaneously increase the vulnerability of sex workers to violence, unintended pregnancies, and HIV and STI transmission, while decreasing their access to SRH services. Fearing legal repercussions such as arrest, detention, and loss of child custody, sex workers 
were found to avoid seeking vital SRH care at critical moments across their life course. A Rwandan sex worker described how the criminalisation of sex work in Rwanda prevented her from accessing post-exposure prophylaxis, as well as legal recourse, after being raped by police officers.

Late one night, I was arrested by two police officers who asked me to have sex with them in case I wanted to be set free. When I refused, one of them forced himself on me and raped me. I had nowhere to report since sex work is illegal under the Rwandan penal code. Because of this, I couldn't even get post-exposure prophylaxis that is offered to all rape victims. Thankfully, I didn't get pregnant... But I tested HIV positive. I couldn't believe it since I had tried to protect myself against HIV all the years I was in sex work. I went back for another test, which confirmed my status. To get infected through rape was heartbreaking.-Female sex worker, Rwanda

Criminalisation was also found to fuel stigma and discrimination among healthcare providers, coalescing with moral judgements surrounding sexuality, gender, and parenthood. Stigma and discrimination were particularly prevalent in public SRH care settings, where medical staff seldom receive sensitivity training surrounding sex workers' health concerns. Upon disclosure or outing of their profession, many sex workers reported changes in the attitude of staff towards them, lower quality of care, or even denial of services.

I went to the ER with a lot of abdominal pain and was denied services because I was a sex worker. They told me they had to finish with the rest of their patients first before providing me with assistance.-Female sex worker, Peru

I was sent back number of times by the health providers when I went in for family planning because most of the time I was drunk and a very well-known sex worker. I was told to change the person I am, and only then can I be helped.-Female sex worker, Namibia

Due to widespread homophobia and transphobia, male and transgender sex workers face even greater stigma and discrimination in SRH care settings.

... The doctor... lifted up my pullover and noticed that I had no breasts. She started telling me that my lifestyle was wrong. I was born a man and thus I should be a man. I shouldn't wear skirts or use makeup... After that incident I am really scared of going to a clinic.Transgender sex worker, Kyrgyzstan

As a result, many sex workers chose not to disclose their profession to healthcare workers, or they avoided seeking care altogether.

\section{Lack of Tailored and Integrated SRH Services}

By and large, the NSWP community consultation confirmed that the healthcare available to sex workers remained limited in scope and failed to address the population-specific SRH concerns. Comprehensive SRH services, including pregnancy care, reproductive cancer screening, and hormone therapy, were rarely integrated with HIV and STI programmes, requiring sex workers to travel to multiple locations to address their various concerns. Moreover, as public health services were aimed 
towards the general population, and specialised non-governmental SRH programmes remained scarce, critical gaps persisted in the coverage of sex workers' SRH care.

In Nepal, where a large portion of female sex workers have been affected by cervical cancer, the lack of information and accessible SRH services was reported to contribute to higher mortality rates.

... (Sex workers) are not very aware of treatment for cervical cancer, as they think that it cannot be detected in advance. They have seen that many female sex workers have died of cervical cancer... There are only a few clinics for female sex workers that are providing free cervical screenings, and they are difficult to reach from residential areas.-Jagriti Mahila Maha Sangh, Nepal

The unique SRH needs of male and transgender sex workers were rarely addressed in both public and non-governmental health settings, exacerbating inequities and isolation for these populations. As one male sex worker described,

In SRH services, we male sex workers have no type of access... because we are not considered within the health care system... We are struggling to be included in health care programs specific to our work activities and our masculinities. We can only access health care as MSM (men who have sex with men), and only from a pathologized approach in HIV/ AIDS, not in an integrated way.-Asociación Goover, Ecuador

The lack of targeted, non-judgemental SRH care also increased sex workers' reliance on self-medication. Due to the unavailability of supervised hormone therapy and other gender-affirming treatments, many transgender sex workers chose to self-medicate, risking long-term health consequences such as thromboembolism, liver dysfunction, breast cancer, and coronary artery disease. The sharing and reusing of injection supplies may also put transgender sex workers at greater risk of HIV and Hepatitis $\mathrm{C}$ transmission.

We, trans women ... have to buy syringes used by veterinarians so that we can inject hormones, since in our country, in our region, there is no hormone treatment.-Transgender sex worker, Peru

\section{Harmful and Coercive SRH Policies}

Mandatory testing and treatment of HIV and STI occur in many regions of the world where sex work is legalised and criminalised. This violates the bodily integrity of sex workers and reinforces unequal power dynamics between provider and patient. In Austria, sex workers explained that, in order to work legally, they were required to undergo weekly STI tests and quarterly HIV tests at government-run facilities. This policy eroded their trust in healthcare systems, and discouraged sex workers from speaking openly about their SRH concerns.

This (testing) center is more of a (means) to control sex workers' bodies than it is a healthcare and counseling space.-Sex worker, Austria 
Even in the absence of formal mandatory testing and treatment policies, coercive practices were still widespread. In Ecuador, health centres frequently required sex workers to take HIV and STI tests in order to receive free condoms-undermining the concept of voluntary testing and further restricting access to already-limited sexual health supplies.

In our country there is a practice to obtain condoms, which is to force us to take a voluntary test, and only then can we access condoms. There is also a shortage of (prevention) supplies and many problems to obtain them. - Coalición de Trabajadores Sexuales de Quito, Ecuador

In other cases, healthcare professionals forced or coerced sex workers into undergoing abortions or sterilisation procedures, blatantly infringing upon their bodily integrity and right to bear children. At the same time, in regions of the world where abortion is prohibited or restricted, sex workers may risk their lives and health by using illegal service providers. While the criminalisation of abortion affects all women, sex workers may be particularly impacted by this due to their increased susceptibility to sexual violence and reduced access to contraceptives.

Every type of abortion is punishable and sex workers, if they want to practice, have to go to clandestine clinics where they risk their lives and health.-Asociacion de Mujeres Las Golondrinas, Nicaragua

\section{Logistical and Practical Barriers to SRH Care}

Given that the majority of SRH services available to sex workers are offered at public healthcare centres targeting the general population, the location of clinics, their opening hours, and the fees they charged were often found to be incompatible with the reality of sex workers' lives.

A typical situation is such that after working at night, sex workers sleep during the day, and the opening hours, for example, of the state dermatovenereological center, are only until 3pm.-Tais Plus, Kyrgyzstan

To address their various needs, many sex workers needed to travel long distances due to SRH services being scattered across multiple locations. Sex workers explained that this factor could result in reduced uptake and adherence, as well as income loss. For individuals living in rural or poorly resourced areas, these logistical barriers were compounded.

A very small percentage of (sex workers) referred to HIV testing centers from general clinics will actually arrive there at the end of the day.-Avenir Jeune de l'Ouest, Cameroon

Some sex workers described accessing select SRH services at mobile health clinics located near their places of work. While convenient, some of these clinics were poorly designed, with inadequate consideration given to sex workers' privacy. As a result, sex workers who relied on these clinics for their SRH care may not have been afforded the same level of confidentiality as patients from the general population. 
I receive my results in the corner of the room and I'm scared that the others will hear something about me... when we do VCT (voluntary counseling and testing) in this facility they should partition the room... not give us our results in the corner of an open room where others can listen.-Female sex worker, Indonesia

Costs for comprehensive SRH care, including non-barrier contraceptives, maternity care, abortion, hormone therapy, PrEP, and other medications, were found to be prohibitive for some sex workers. Even where affordable subsidised SRH care was available, many sex workers lacked the necessary identification, residency, or employment documents to benefit from these programmes. In countries where sex work is a regulated profession, such as Austria, mandatory national health insurance costs were found to be inaccessible for some sex workers, and did not always cover essential services such as maternity care.

Some months, I don't earn so much. I can't afford to pay the bill (the Social Security Service) sends me.-Sex worker, Austria

\section{Supporting the SRH Rights and Needs of SWs: Community Recommendations}

Grounded in the lived experiences of sex workers globally, these narratives shed light on the tremendous impact that overlapping structural barriers play in constraining sex workers' access to comprehensive, rights-based SRH services. Echoing international guidelines, the sex workers and sex worker-led organisations participating in the NSWP consultation highlighted a number of recommendations to better support the SRH needs and rights of sex workers [58]:

1. "Decriminalize sex work, HIV transmission, and same-sex sexual activity, and depathologize transgender identities". [58]

The criminalisation of sex work, same-sex relationships, and HIV continues to trigger a cascade of harms, including reduced access to SRH services due to fears of legal repercussions, judgement, or harassment. As such, participants pointed to the decriminalisation of sex work as essential to improving sex workers' SRH and rights [58].

A decriminalised legal framework can promote the SRH and rights of sex workers in a number of ways. Alongside mitigating the harms of stigma within communities and healthcare settings, the legal empowerment of sex workers, LGBTQ people, and people living with HIV can support sex workers' ability to organise and advocate for conditions and SRH services that best suit their needs [59]. Decriminalisation of sex work can facilitate the implementation of sex worker-led structural SRH interventions, including access to safer indoor workplaces. Such access may subsequently enable the provision of rights-based SRH services at or close to sex work venues, confer protection from client-perpetrated violence, and offer a level of control and privacy necessary to fulfil sex workers' reproductive rights $[60,61]$. The Global Network of Sex Work Projects has 
advocated for the decriminalisation of sex work for 25 years. Numerous international organisations have followed suit in recommending decriminalisation, including WHO, UNAIDS, UNFPA, UNDP, and Amnesty International [62].

2. "Remove barriers to accessing public health care systems for migrant sex workers, as well as individuals who cannot provide formal proof of income or employment". [58]

Restrictions surrounding public health services prevent sex workers from accessing essential SRH care. As a result, migrant sex workers may depend on limited NGO programming or emergency-room services for their SRH needs.

3. "Eliminate mandatory and coercive HIV and STI testing and treatment policies". [58]

The pervasive stigma around sex work, including portrayals of sex workers as vectors of disease, often manifests as mandatory and/or coercive HIV/STI testing policies [63]. Coercive HIV testing, or the surreptitious testing for HIV by healthcare workers or police without obtaining consent from sex workers [6466], violates sex workers' rights to bodily integrity. Such practices also foster their distrust in authorities and further excludes sex workers from vital SRH services. Similarly, mandatory HIV/STI testing policies also undermine the right of sex workers to make autonomous choices regarding their own SRH.

Sex workers when consulted recommended the elimination of mandatory and coercive HIV/STI testing and treatment policies, including HIV/STI testing and treatment without consent. These recommendations strongly align with the WHO and UNAIDS statement on HIV testing and counselling, which opposes mandatory and coercive HIV and STI testing, and emphasises the importance of adhering to the "5 C's"- consent, confidentiality, counselling, correct test results, and connection/linkage to prevention care and treatment [67].

4. "Address the stigma and discrimination that female, male and transgender sex workers experience from mainstream SRH services". [58]

Stigma and discrimination remain pervasive in SRH health settings, particularly mainstream services, and continue to hamper access to and retention in, care. To support the SRH rights of sex workers, healthcare providers should receive specialised training focused on providing non-judgemental and gendersensitive care tailored to the needs of the sex workers of all genders. Qualitative findings from Argentina suggest that specialised healthcare provider training focused on the needs of cis and transgender sex workers has improved providerpatient relationships and has contributed to increased uptake and continued engagement in HIV care [65].

Addressing stigma and discrimination within SRH care settings is crucial. However, multilevel interventions, including structural interventions, are essential to stemming stigma relating to sex work, gender, and HIV status within the community.

A promising policy intervention to reduce gender-based stigma towards transgender sex workers is Argentina's "Gender Identity Law", rolled out 2012, which acknowledges the basic right of transgender individuals to personhood. The law recommends universal coverage for transition-related health care and 
allows individuals to change their name on legal documents (e.g. identity cards and birth certificates). Since this law was enacted, reports from transgender sex workers suggest improved patient-provider attitudes and relationships, and improved access to health care [66], including retention in HIV care. Acknowledging that a shift in attitudes on the part of the community and care providers takes time, there is an immediate need for the development of sex worker-led systems to redress the ongoing stigma experienced by sex workers within healthcare settings [58].

5. "Increase funding and support for comprehensive SRH services and programs designed to meet the needs of sex workers of all genders". [58]

Advance a holistic approach to comprehensive SRH services for sex workers that extends beyond HIV and STI testing and treatment. [58]

In line with UNAIDS recommendations [66], there is a need to improve funding for and access to comprehensive, sex worker-specific SRH services, which should be integrated with other essential services, including HIV/STI programming. Moving away from a strict focus on HIV/STI services, there is a need for comprehensive services that holistically address sex workers' broader SRH needs and rights, as defined in the Sex Worker Information Tool (SWIT) [38].

6. "Ensure access to safe, legal, and affordable abortion and post-abortion services". [58]

Action is needed to ensure access to safe and affordable abortion and postabortion care for sex workers. Restrictions on abortion may lead women to risk their health through the use of informal methods of termination.

7. "Integrate SRH care with HIV and STI services in line with a 'one-stop-shop' model". [58]

To address logistical barriers to accessing services, including the need to travel long distances to obtain fragmented services, sex workers highlighted the need for SRH services to be integrated into HIV and STI services in a "one-stopshop" model. While questions remain regarding the best model for SRH service integration, and more evaluations of the effectiveness of integrated SRH models are needed [53], emerging research suggests such an approach could improve uptake of broader SRH services $[49,68,69]$.

8. "Promote SRH education programming for sex workers and their clients". [58]

Targeted SRH information is essential to fulfiling the right of sex workers to informed SRH decisions and improving their access to SRH services. SRH education targeting clients, particularly surrounding safe sex practices, is also critical, and reduces the burden of educating clients that sex workers currently shoulder.

9. "Prioritize funding for community empowerment models of SRH services". [58]

It is imperative that the voices of sex workers steer the development and implementation of SRH programmes and services affecting them. Communityled SRH models can take many forms, including outreach programmes, drop-in centers, peer educators and navigators, and sensitisation trainings for medical personnel, with sex workers' collective ownership being a hallmark of these initiatives. Community-led HIV/STI approaches have been linked to positive 
SRH outcomes, including reduced HIV/STIs and increased condom use by clients, while also addressing social and structural barriers to SRH and rights [58].

Sex worker-led interventions that empower sex workers and foster community engagement with key stakeholders have also been found to help reduce stigma and violence towards sex workers $[68,69]$. In collaboration with Durbar Mahila Samanwaya Committee, the Sonagachi project in Kolkata is an example of such an approach. The multifaceted intervention included a number of key components, including community-level interventions that: articulated sex workers' rights; involved sex workers as staff, programme leaders, key decisionmakers; and facilitated the sex workers' organisation as an occupational employment group [70]. Together, these initiatives contributed to improving sex workers' collective social power and reducing stigma [70]. Another important feature of Sonagachi's success and sustainability included the involvement of and careful negotiations between sex workers and influential "non-sex worker" interest groups, for example, madams, local clubs, healthcare providers, and funding agencies. Acknowledging and managing existing power relations in this manner has had numerous benefits, including the reduction of stigma [71]. This important work is being continued by the Durbar Mahila Samanwaya Committee.

Despite the immense promise that community-empowerment models hold, increased political and financial support for community-led SRH models is urgently needed, alongside the removal of regressive policies (e.g. PEPFAR APLO, Mexico City Policy) and laws (e.g. the criminalisation of sex work), which impede sex workers' ability to organise, and limit the funding and scope of sex worker-led SRH services [58].

\section{Conclusion}

Sex workers around the world continue to face serious SRH inequities, which are shaped by a lack of comprehensive, integrated, and non-judgemental SRH care tailored to their diverse needs. To date, the broader SRH needs of sex workers have been neglected, with existing efforts focused narrowly on HIV/STI prevention. Limited access for sex workers to comprehensive and integrated SRH services represents a serious violation of their fundamental right to obtain the highest attainable standards of SRH. This limitation points to the urgent need for political action to close these gaps. Such efforts need to tackle the structural barriers that drive gaps in the SRH of sex workers, including criminalisation and other rights-violating policies, stigma, and violence. At the same time, these efforts must empower sex workers to shape and lead the SRH policies and programming that affect them.

Conflicts of Interest The authors have no conflicts of interest to declare. 


\section{References}

1. UN General Assembly. Convention on the elimination of all forms of discrimination against women; 1979.

2. UN Committee on Economic, Social, and Cultural Rights. General Comment No. 22 (2016) on the right to sexual and reproductive health (article 12 of the International Covenant on Economic, Social, and Cultural Rights); 2016.

3. Women Fourth World Conference on Women. Beijing declaration and platform for action; 1995. p. 93-7.

4. Eleventh International Conference of the International Coordinating Committee of National Institutes for the Promotion and Protection of Human Rights. Amman Declaration and Programme of Action; 2012.

5. UN General Assembly. Universal declaration of human rights; 1948.

6. International Conference on Population and Development. Programme of action; 1994.

7. UN General Assembly. Transforming our world: the 2030 Agenda for Sustainable Development; 2015.

8. Shannon K, Rusch M, Shoveller J, Alexson D, Gibson K, Tyndall MW. Mapping violence and policing as an environmental-structural barrier to health service and syringe availability among substance-using women in street-level sex work. Int J Drug Policy. 2008;19(2):140-7.

9. Platt L, Grenfell P, Meiksin R, Elmes J, Sherman SG, Sanders T, et al. Associations between sex work laws and sex workers' health: a systematic review and meta-analysis of quantitative and qualitative studies. PLoS Med. 2018;15(12):e1002680.

10. Lyons T, Krusi A, Pierre L, Smith A, Small W, Shannon K. Experiences of trans women and two-spirit persons accessing women-specific health and housing services in a downtown neighborhood of Vancouver, Canada. LGBT Health. 2016;3(5):373-8.

11. Duff P, Birungi J, Dobrer S, Akello M, Muzaaya G, Shannon K. Social and structural factors increase consistent condom use by sex workers' one-time and regular clients in Northern Uganda. AIDS Care. 2018;30(6):751-9.

12. Shannon K, Strathdee SA, Goldenberg SM, Duff P, Mwangi P, Rusakova M, et al. Global epidemiology of HIV among female sex workers: influence of structural determinants. Lancet. 2015;385(9962):55-71.

13. Iran Official Calls for Sterilization for Sex Workers, Homeless Drug Addicts. Radio free Europe; 2017.

14. Qiao S, Li X, Zhang C, Zhou Y, Shen Z, Tang Z, et al. Psychological fears among low-paid female sex workers in southwest China and their implications for HIV prevention. PLoS One. 2014;9(10):e111012.

15. Anderson S, Shannon K, Li J, Lee Y, Chettiar J, Goldenberg S. Condoms and sexual health education as evidence: impact of criminalisation of in-call venues and managers on migrant sex workers access to HIV/STI prevention in a Canadian setting. BMC Int Health Hum Rights. 2016;16(1):30.

16. Deering KN, Amin A, Shoveller J, Nesbitt A, Garcia-Moreno C, Duff P, et al. A systematic review of the correlates of violence against sex workers. Am J Public Health. 2014;104(5):e42-54.

17. Baral S, Holland CE, Shannon K, Logie C, Semugoma P, Sithole B, et al. Enhancing benefits or increasing harms: community responses for HIV among men who have sex with men, transgender women, female sex workers, and people who inject drugs. J Acquir Immune Defic Syndr. 2014;66(Suppl 3):S319-28.

18. Krüsi A, Kerr T, Taylor C, Rhodes T, Shannon K. 'They won't change it back in their heads that we're trash': the intersection of sex work-related stigma and evolving policing strategies. Sociol Health Illn. 2016;38(7):1137-50.

19. Rocha-Jimenez T, Morales-Miranda S, Fernandez-Casanueva C, Brouwer KC, Goldenberg SM. Stigma and unmet sexual and reproductive health needs among international migrant sex workers at the Mexico-Guatemala border. Int J Gynaecol Obstet. 2018;143(1):37-43. 
20. King EJ, Maman S, Bowling JM, Moracco KE, Dudina V. The influence of stigma and discrimination on female sex workers' access to HIV services in St. Petersburg, Russia. AIDS Behav. 2013;17(8):2597-603.

21. Lazarus L, Deering KN, Nabess R, Gibson K, Tyndall MW, Shannon K. Occupational stigma as a primary barrier to health care for street-based sex workers in Canada. Cult Health Sex. 2012;14(2):139-50.

22. Crowell TA, Keshinro B, Baral SD, Schwartz SR, Stahlman S, Nowak RG, et al. Stigma, access to healthcare, and HIV risks among men who sell sex to men in Nigeria. J Int AIDS Soc. 2017;20(1):21489.

23. Nnko S, Kuringe E, Nyato D, Drake M, Casalini C, Shao A, et al. Determinants of access to HIV testing and counselling services among female sex workers in sub-Saharan Africa: a systematic review. BMC Public Health. 2019;19(1):15.

24. Scorgie F, Nakato D, Harper E, Richter M, Maseko S, Nare P, et al. 'We are despised in the hospitals': sex workers' experiences of accessing health care in four African countries. Cult Health Sex. 2013;15(4):450-65.

25. Dhana A, Luchters S, Moore L, Lafort Y, Roy A, Scorgie F, et al. Systematic review of facilitybased sexual and reproductive health services for female sex workers in Africa. Glob Health. 2014;10(1):46.

26. Soohoo M, Blas M, Byraiah G, Carcamo C, Brown B. Cervical HPV infection in female sex workers: a global perspective. Open AIDS J. 2013;7:58-66.

27. Mak R. Cervical smears and human papillomavirus typing in sex workers. Sex Transm Infect. 2004;80(2):118-20.

28. Duff P, Ogilvie G, Shoveller J, Amram O, Chettiar J, Nguyen P, et al. Barriers to cervical screening among sex workers in Vancouver. Am J Public Health. 2016;106(2):366-73.

29. Jeal N, Salisbury C. Self-reported experiences of health services among female street-based prostitutes: a cross-sectional survey. Br J Gen Pract. 2004;54(504):515-9.

30. Baral SD, Friedman MR, Geibel S, Rebe K, Bozhinov B, Diouf D, et al. Male sex workers: practices, contexts, and vulnerabilities for HIV acquisition and transmission. Lancet. 2015;385(9964):260-73.

31. GNP+ and Network of Sex work Projects (NSWP). Advancing the sexual and reproductive health and human rights of sex workers living with HIV; 2010.

32. MacCarthy S, Poteat T, Xia Z, Roque NL, Hyun Jin Kim A, Baral S, et al. Current research gaps: a global systematic review of HIV and sexually transmissible infections among transgender populations. Sex Health. 2017;14(5):456-68.

33. Baral SD, Poteat T, Stromdahl S, Wirtz AL, Guadamuz TE, Beyrer C. Worldwide burden of HIV in transgender women: a systematic review and meta-analysis. Lancet Infect Dis. 2013;13(3):214-22.

34. Shannon K, Crago AL, Baral SD, Bekker LG, Kerrigan D, Decker MR, et al. The global response and unmet actions for HIV and sex workers. Lancet. 2018;392(10148):698-710.

35. Reisner SL, Poteat T, Keatley J, Cabral M, Mothopeng T, Dunham E, et al. Global health burden and needs of transgender populations: a review. Lancet. 2016;388(10042):412-36.

36. Poteat T, Scheim A, Xavier J, Reisner S, Baral S. Global epidemiology of HIV infection and related syndemics affecting transgender people. J Acquir Immune Defic Syndr. 2016;72(Suppl 3):S210-9.

37. Reisner SL, Bradford J, Hopwood R, Gonzalez A, Makadon H, Todisco D, et al. Comprehensive transgender healthcare: the gender affirming clinical and public health model of Fenway Health. J Urban Health. 2015;92(3):584-92.

38. World Health Organization, UNFP, Joint United Nations Programme on HIV/AIDS, Global Network of Sex Work Projects, The World Bank. Implementing comprehensive HIV/STI programmes with sex workers: practical approaches from collaborative interventions. Geneva: WHO; 2013.

39. Ampt FH, Willenberg L, Agius PA, Chersich M, Luchters S, Lim MSC. Incidence of unintended pregnancy among female sex workers in low-income and middle-income countries: a systematic review and meta-analysis. BMJ Open. 2018;8(9):e021779. 
40. Delvaux T, Crabbe F, Seng S, Laga M. The need for family planning and safe abortion services among women sex workers seeking STI care in Cambodia. Reprod Health Matters. 2003;1(21):88-95.

41. Bautista CT, Mejia A, Leal L, Ayala C, Sanchez JL, Montano SM. Prevalence of lifetime abortion and methods of contraception among female sex workers in Bogota, Colombia. Contraception. 2008;1(3):209-13.

42. Todd CS, Alibayeva G, Sanchez JL, Bautista CT, Carr JK, Earhart KC. Utilization of contraception and abortion and its relationship to HIV infection among female sex workers in Tashkent, Uzbekistan. J Womens Health. 2006;1(4):318-23.

43. Duff P, Evans JL, Stein ES, Page K, Maher L, Young Women's Health Study Collaborative. High pregnancy incidence and low contraceptive use among a prospective cohort of female entertainment and sex workers in Phnom Penh, Cambodia. BMC Pregnancy Childbirth. 2018;1(1):128.

44. Khan MR, Turner AN, Pettifor A, Van Damme K, Rabenja NL, Ravelomanana N, et al. Unmet need for contraception among sex workers in Madagascar. Contraception. 2009;1(3):221-7.

45. Martin CE, Wirtz AL, Mogilniy V, Peryshkina A, Beyrer C, Decker MR. Contraceptive use among female sex workers in three Russian cities. Int J Gynaecol Obstet. 2015;1(2):156-60.

46. Todd CS, Nasir A, Raza Stanekzai M, Scott PT, Strathdee SA, Botros BA, et al. Contraceptive utilization and pregnancy termination among female sex workers in Afghanistan. J Womens Health. 2010;1(11):2057-62.

47. Zhang XD, Kennedy E, Temmerman M, Li Y, Zhang WH, Luchters S. High rates of abortion and low levels of contraceptive use among adolescent female sex workers in Kunming, China: a cross-sectional analysis. Eur J Contracept Reprod Health Care. 2014;1(5):368-78.

48. Luchters S, Bosire W, Feng A, Richter ML, King'ola N, Ampt F, et al. "A baby was an added burden": predictors and consequences of unintended pregnancies for female sex workers in Mombasa, Kenya: a mixed-methods study. PLoS One. 2016;1(9):e0162871.

49. Schwartz S, Papworth E, Thiam-Niangoin M, Abo K, Drame F, Diouf D, et al. An urgent need for integration of family planning services into HIV care: the high burden of unplanned pregnancy, termination of pregnancy, and limited contraception use among female sex workers in Cote d'Ivoire. J Acquir Immune Defic Syndr. 2015;1:S91-8.

50. Madeiro AP, Diniz D. Induced abortion among Brazilian female sex workers: a qualitative study. Cien Saude Colet. 2015;1(2):587-93.

51. Erickson M, Goldenberg SM, Akello M, Muzaaya G, Nguyen P, Birungi J, et al. Incarceration and exposure to internally displaced persons camps associated with reproductive rights abuses among sex workers in northern Uganda. J Fam Plann Reprod Health Care. 2017;1(3):201-9.

52. Feldblum PJ, Nasution MD, Hoke TH, Van Damme K, Turner AN, Gmach R, et al. Pregnancy among sex workers participating in a condom intervention trial highlights the need for dual protection. Contraception. 2007;1(2):105-10.

53. Schwartz SR, Baral S. Fertility-related research needs among women at the margins. [Review]. Reprod Health Matters. 2015;1(45):30-46.

54. Elmore-Meegan M, Conroy RM, Agala CB. Sex workers in Kenya, numbers of clients and associated risks: an exploratory survey. Reprod Health Matters. 2004;1(23):50-7.

55. Duff P, Shoveller J, Feng C, Ogilvie G, Montaner J, Shannon K. Pregnancy intentions among female sex workers: recognising their rights and wants as mothers. J Fam Plann Reprod Health Care. 2015;1(2):102-8.

56. Schwartz SR, Papworth E, Ky-Zerbo O, Anato S, Grosso A, Ouedraogo HG, et al. Safer conception needs for HIV prevention among female sex workers in Burkina Faso and Togo. Infect Dis Obstet Gynecol. 2014;1:296245.

57. Global Commission on HIV and the law. HIV and the law: risks, rights, \& health; 2012.

58. Global Network of Sex Work Projects. Briefing Paper: Sex workers' access to comprehensive sexual and reproductive health services; 2018.

59. Kerrigan D, Kennedy CE, Morgan-Thomas R, Reza-Paul S, Mwangi P, Win KT, et al. A community empowerment approach to the HIV response among sex workers: effectiveness, challenges, and considerations for implementation and scale-up. Lancet. 2014;6736(14):1-14. 
60. Goldenberg SM, Duff P, Krusi A, Shannon K. Work environments and HIV prevention: a qualitative review and meta-synthesis of sex worker narratives. BMC Public Health. 2015;15:1241.

61. Duff P, Shoveller J, Dobrer S, Ogilvie G, Montaner J, Chettiar J, et al. The relationship between social, policy and physical venue features and social cohesion on condom use for pregnancy prevention among sex workers: a safer indoor work environment scale. J Epidemiol Community Health. 2015;69(7):666-72.

62. WHO, UNFPA, UNAIDS, NSWP. Prevention and treatment of HIV and other sexually transmitted infections for sex workers in low- and middle-income countries. Geneva, Switzerland: WHO, UNFPA, UNAIDS, NSWP; 2012.

63. Tokar A, Broerse JEW, Blanchard J, Roura M. HIV testing and counseling among female sex workers: a systematic literature review. AIDS Behav. 2018;22(8):2435-57.

64. Duff P, Supriyadinata C, Rowe C, Maher L, Nanditha N, Sarahdita T, et al. Supporting patient rights and informed consent in the context of HIV testing and treatment scale-up: experiences of female sex workers living with HIV in Bali, Indonesia. International AIDS Society Conference, Amsterdam; 2018.

65. Zalazar V, Cardozo N, Socias E, Aristegui I, Frola C, Antonini C, et al. Community perspectives on supporting the ethical scale-up of HIV services among transgender women in Argentina in the context of Treatment as Prevention. International AIDS Conference, Paris, France; 2017.

66. Aristegui I, Radusky P, Zalazar V, Romero M, Schwartz J, Sued O. Impact of the Gender Identity Law in Argentinean transgender women. Int J Transgenderism. 2017;18(4):446-56.

67. World Health Organization. Statement on HIV testing and counseling: WHO, UNAIDS reaffirm opposition to mandatory HIV testing. World Health Organization. 2012. Available from: https://www.who.int/hiv/events/2012/world_aids_day/hiv_testing_counselling/en/.

68. Beattie TSH, Bhattacharjee P, Ramesh BM, Gurnani V, Anthony J, Isac S, et al. Violence against female sex workers in Karnataka state, south India: impact on health, and reductions in violence following an intervention program. BMC Public Health. 2010;10:476.

69. Reza-Paul S, Beattie T, Syed HU, Venukumar KT, Venugopal MS, Fathima MP, et al. Declines in risk behaviour and sexually transmitted infection prevalence following a community-led HIV preventive intervention among female sex workers in Mysore, India. AIDS. 2008;22(Suppl 5):S91-100.

70. Jana S, Basu I, Rotheram-Borus MJ, Newman PA. The Sonagachi project: a sustainable community intervention program. AIDS Educ Prev. 2004;16(5):405-14.

71. Cornish F, Ghosh R. The necessary contradictions of 'community-led' health promotion: a case study of HIV prevention in an Indian red light district. Soc Sci Med. 2007;64(2):496-507. 
Open Access This chapter is licensed under the terms of the Creative Commons Attribution 4.0 International License (http://creativecommons.org/licenses/by/4.0/), which permits use, sharing, adaptation, distribution and reproduction in any medium or format, as long as you give appropriate credit to the original author(s) and the source, provide a link to the Creative Commons license and indicate if changes were made.

The images or other third party material in this chapter are included in the chapter's Creative Commons license, unless indicated otherwise in a credit line to the material. If material is not included in the chapter's Creative Commons license and your intended use is not permitted by statutory regulation or exceeds the permitted use, you will need to obtain permission directly from the copyright holder. 